J. Mark Ansermino MB FFA(SA),

Peter M. Sanderson MB FRCA, Joan C. Bevan MD FRCA, David R. Bevan MB MRCP FRCA

\section{Acceleromyography improves detection of residual neuromuscular blockade in children}

Purpose: To determine whether detection of residual blockade is improved by using the accelerograph. A secondary objective was to compare acceleromyographic measurements with those obrained by electromyography.

Methods: In a prospective, randomized, double-blind investigation, 22 anaesthetized children were studied during recovery from neuromuscular blockade following $0.1 \mathrm{mg} \cdot \mathrm{kg}^{-1}$ vecuronium iv. Assessments of depth of block began $10 \mathrm{~min}$ after injection and were repeated at one minute intervals using electromyography (Datex, Relaxograph) in one hand, and acceleromyography (Biometer, Tofguard) in the other, to measure responses of the adductor pollicis to train-of-four (TOF) stimulation of the ulnar nerve. Monitoring was stopped when no fade was visible and TOF ratio $\geq 0.7$. The electromyographic (EMG) and acceleromyographic (AMG) data were compared with corresponding observations of the number of twitches and TOF fade in the visible responses of the thumb, made by the attending anuesthetist. The method of Bland and Altman was used to compare differences between AMG and EMG data.

Results: During recovery from neuromuscular blockade, fade was no longer visible clinically $38.6 \pm 10.4 \mathrm{~min}$ (mean $\pm S D$ ) after the administration of vecuronium. This corresponded to

\section{Key words}

ANAESTHESIA: paediatric;

MONITORING: neuromuscular function;

NEUROMUSCULAR RELAXANTS: complications, residual

block.

From the Departments of Anaesthesia, British Columbia's

Children's Hospital and the University of British Columbia,

Vancouver, BC, Canada.

Address correspondence 10: Dr. Joan.C. Bevan, Department of Anaesthesia, British Columbia's Children's Hospital, 4480 Oak Street, Vancouver, BC, V6H 3V4, Canada.

The accelerograph, Tofguard ${ }^{\text {INMT }}$ ( Biometer International A/S, Odense, Denmark) was donaled by Organon Teknika Canada Inc.

Accepted for publication 3I Junuary, 1996.
TOF ratios of $0.40 \pm 0.23$ by $A M G$ and $0.34 \pm 0.21$ by EMG. Usually, two twitches were visible before AMG detected the first twitch. The time to TOF ratio $\geq 0.7$ by $A M G$ and EMG was similar at $49.1 \pm 10.5$ and $50.9 \pm 9.0 \mathrm{~min}$, respectively. The bias between $A M G$ and EMG was one minute, with limits of agreement from -10 to nine min.

Conclusion: $A M G$ is superior to visual assessment in detecting residual neuromuscular block and provides similar estimates of recovering block as the more cumbersome EMG.

Objectifs: Déterminer si l'accélérographie améliore la détection de la curarisation résiduelle. Un deuxième objectif consistait d̀ comparer les données accéléromyographique à celles de l'électromyographie.

Méthodes: Vingt-deux enfants anesthésiés qui avaient reçu vécuronium $0,1 \mathrm{mg} \cdot \mathrm{kg}^{-1}$ iv ont pris part à cette étude aléatoire, prospective et en double aveugle. Dans le but de mesurer les réponses de l'adducteur du pouce au TOF du nerf cubital, l'évaluation de la profondeur de la curarisation a été débutée $10 \mathrm{~min}$ après l'injection et été répétée à toutes les minutes à l'aide d'un accélérographe (Biometer, Tofguard) sur une main et une stimulation au train-de-quarre (TOF) sur l'autre. Le monitorage a été arrêté au moment où l'affaiblissement de la réponse (fade) est disparu et où la relation TOF $\geq 0,7$. L'anesthésiste responsable a comparé les données électromyographiques (EMG) et accéléromyographiques ( $A M G$ ) en observant au niveau du pouce le nombre de nvitches et l'affaiblissement de la réponse. La méthode de Bland et Altman a été utilisée pour comparer les différences entre les données AMG et EMG.

Résultats: Pendant la récupération, l'affaiblissement n'était pas visuellement détectable 38,6 $\pm 10,4 \min$ (moyenne $\pm E T$ ) après l'administration du vécuronium. Ceci correspondait à

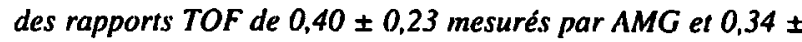
0,21 par EMG. En général, deux nvirches étaient visibles avant la détection par AMG du premier twitch. L'intervalle jusqu'au rapport TOF $\geq 0,7$ était identique, respectivement de 49,1 $\pm 10,5$ et 50,9 $\pm 9,0$ min. Le biais entre $A M G$ et EMG était de une min, avec des limites d'accord de -10 à neuf min. Conclusion: L'AMG est supérieure à l'évaluation visuelle pour détecter la curarisation résiduelle et fournit des données comparables à celles de l'EMG lequel est plus encombrant. 
Ventilatory function, assessed by measurements of peak inspiratory flow, is considered to be restored when the train-of-four ratio (TOF) of the adductor pollicis in response to ulnar nerve stimulation exceeds 0.7 during recovery from d-tubocurarine' or pipecuronium ${ }^{2}$ neuromuscular blockade. This value has become the standard at which to aim to ensure adequate recovery from nondepolarizing neuromuscular block. Unfortunately it is difficult, if not impossible, to detect small degrees of TOF fade using visual or tactile observations. ${ }^{3-5}$ The use of double burst stimulation has reduced, but not eliminated, the magnitude of the discrepancy between clinical estimates and recorded observations of elicited responses. ${ }^{4-7}$ However, more sensitive measurements using mechanomyography (MMG) or electromyography (EMG) are difficult to introduce into routine clinical practice because they are time-consuming and require bulky, expensive equipment. ${ }^{5}$

The assessment of the degree of neuromuscular block by measurement of the acceleration of the thumb in response to ulnar nerve stimulation has recently been introduced into clinical practice. ${ }^{8,9}$ Accelomyography (AMG) is no more difficult or time-consuming to apply than a peripheral nerve stimulator, which is recommended for routine clinical practice. Therefore, AMG may have wider applicability than the mechanomyogram (MMG) or electromyogram (EMG). In addition, it produces a signal that is displayed digitally into a liquid crystal display, allowing it to be integrated into an automated anaesthesia record. It has also been shown that use of AMG prevented the development of residual blockade when it was used to evaluate recovery from pancuronium-induced neuromuscular blockade. ${ }^{10}$

The purpose of the present study was to compare the use of AMG with clinical evaluation of recovery from vecuronium-induced neuromuscular block in children during anaesthesia. In addition, AMG measurements were compared with simultaneous EMG measurements obtained from the contralateral hand.

\section{Methods}

After institutional ethics committee approval and informed parental consent, 29 children, aged 2-10 yr and ASA physical status 1 or 2 , were enrolled into the study. They were admitted for elective day care surgery under general anaesthesia for dental restorative procedures with anticipated durations of at least one hour. None was receiving medication or suffered from disease known to affect neuromuscular transmission.

Children who were upset or anxious on admission received premedication of midazolam $0.5 \mathrm{mg} \cdot \mathrm{kg}^{-1}$ po 15-30 min before surgery. On arrival in the operating room, routine monitoring (electrocardiogram, non-inva- sive blood pressure recording, pulse oximetry and axillary temperature) was applied. The blood pressure cuff was placed on the leg. Local anaesthetic cream on the dorsum of the hand facilitated insertion of an intravenous cannula, which was located on either hand and attached to an extension tube to provide a remote injection site for injection of drugs or saline to flush the line. Anaesthesia was induced with propofol $3-5 \mathrm{mg} \cdot \mathrm{kg}^{-1}$, lidocaine $0.3 \mathrm{mg} \cdot \mathrm{kg}^{-1}$ and fentanyl $2-3 \mu \mathrm{g} \cdot \mathrm{kg}^{-1} \mathrm{iv}$, followed by maintenance with inhalation of isoflurane (0.5-1\% inspired concentration), nitrous oxide $70 \%$ and oxygen mixtures. Nasotracheal intubation was performed without the use of relaxants, using an uncuffed nasotracheal tube. The lungs were ventilated to maintain normocapnia based on end-tidal carbon dioxide concentrations measured by capnometry. On completion of the study period, anaesthesia was conducted at the discretion of the attending anaesthetist until the end of surgery.

Patients were assigned randomly to have the EMG or AMG positioned on the left or right hand. Stimulating surface electrodes were applied over the ulnar nerves in the forearm near the wrists of both hands. Palmar skin temperatures were monitored and skin temperature was maintained $\geq 34^{\circ} \mathrm{C}$. The EMG recording electrodes were applied over the adductor pollicis muscle of one hand and the AMG transducer was applied to the opposite hand on the palmar surface of the distal phalanx of the thumb. Both arms were wrapped in towelling to maintain limb temperature and dorsal splints were used to immobilize the forearms and fingers, but free movement of the thumb was ensured for the AMG monitor. Supramaximal stimuli of $0.1 \mathrm{msec}$ duration in TOF mode at $2 \mathrm{~Hz}$ were applied every $20 \mathrm{sec}$ for the EMG, using the Datex Relaxograph NMT 100 (Datex Instrumentarium Corporation, Helsinki, Finland) and every $15 \mathrm{sec}$ for the AMG, using the Tofguard ${ }^{\text {INMT }}$ (Biometer Intenational A/S, Odense, Denmark) monitors. After ten minutes stabilization, the neuromuscular monitors were calibrated.

After repeat calibration, vecuronium $0.1 \mathrm{mg} \cdot \mathrm{kg}^{-1}$ iv was administered, taking care to avoid moving the hand into which the injection was made. Ten minutes after the administration of vecuronium, when neuromuscular blockade was established, measurements of first twitch height $\left(T_{1}\right)$ and TOF fade were commenced and made simultaneously by AMG, EMG and visual estimates of thumb movement, on the same side as the AMG, by one of three participating attending anaesthetists who was blinded to the monitor displays. These observations were repeated at one minute intervals, during recovery from neuromuscular blockade, until TOF fade was no longer detectable clinically and monitoring by AMG 
and EMG showed $\mathrm{T}_{1}$ height recovery $\geq 70 \%$ of control and TOF ratio $\mathbf{2 0 . 7}$, or these values had reached a plateau and showed no further recovery on three consecutive readings.

Data were collected during the study period on a computer-based spreadsheet (Microsoft Excel V5.0). Demographics (date of birth, weight, height, sex) and times of induction of anaesthesia, administration of vecuronium, onset and cessation of monitoring were recorded. Entries of data for $T_{1}$ and TOF ratios, monitored by AMG or EMG, and estimated visually, were made at the time of monitoring. Values are expressed as mean \pm SD. Statistical analysis was performed using paired Student $t$ test, chi-squared analysis and Fisher exact test where appropriate. Agreement between the monitors was assessed by the methods of Bland and Altman. ${ }^{11,12}$ These assess the extent of the agreement between two different methods of clinical measurement by calculating the mean of the differences between the values obtained by the two methods (bias) and the SD of the differences. Simple plots of the simultaneous recordings of measurements by EMG and AMG and their lines of identity, and plots of the mean of the two values against the difference between the paired measurements were used for this method of analysis.

\section{Results}

Data collection was completed on 22 of 29 children who were enrolled into the study: seven were excluded from analysis because surgery ended before the study could be completed in four and EMG recordings were unsatisfactory in three patients. The 22 patients studied were 11 boys: 11 girls, aged $5 \pm 1.6 \mathrm{yr}$ and weighed $20.3 \pm 5.3$ kg.

\section{Recovery of first twitch}

First twitch response usually appeared first on the EMG and was present before any twitches were visible. Estimates of recovery of $T_{1}$ by the visual observation of the thumb by the anaesthetist or retum of EMG activity preceded the AMG response. On average, two twitches of the thumb were observed before the first twitch appeared on the AMG response (Figure 1).

\section{Recovery of train-of-four}

During recovery from neuromuscular blockade, fade of TOF was no longer visible $38.6 \pm 10.4 \mathrm{~min}$ after the injection of vecuronium, when the measured TOF ratio was $0.40 \pm 0.23$ by AMG and $0.34 \pm 0.21$ by EMG. All except three of the EMG values were $<0.5$. On recovery of the TOF to $>0.7$, measured by AMG, only one child still showed a TOF ratio $<0.5$ by EMG (Figure 2 ).

There were 568 paired values for the TOF ratios mea-

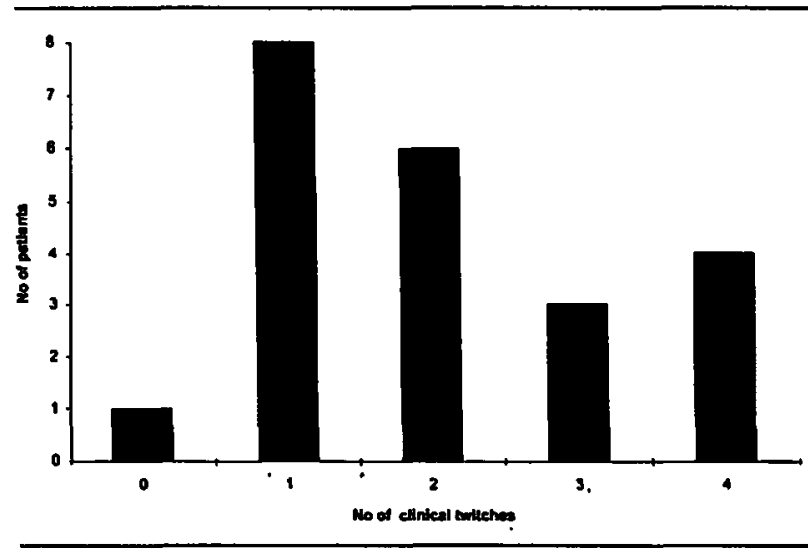

FIGURE I Distribution of the number of twitches seen on visual inspection clinically when the first twitch is detected by AMG monitoring.

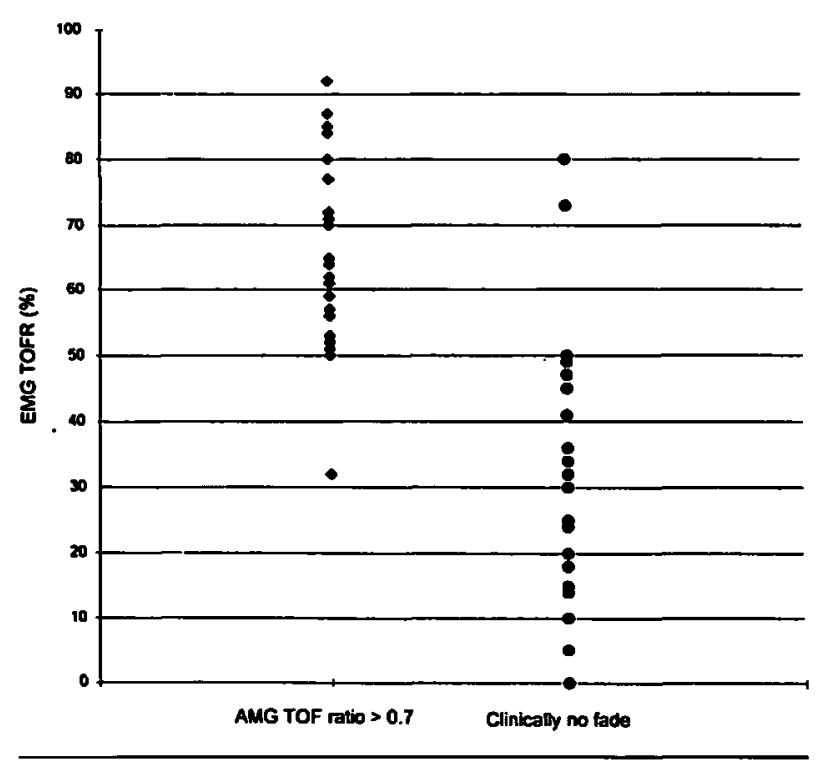

FIGURE 2 Value of TOF ratio monitored by EMG when the AMG shows a TOF ratio $>0.7$ and when no fade was detected clinically.

sured by AMG and EMG (Figure 3). Plots of the difference between the paired measurements against the mean (Figure 4), showed that the bias between the sensors was 0.03, with AMG higher than EMG. Limits of agreement were -0.26 to 0.32 and the $95 \%$ confidence interval for the bias was $0.02-0.04$.

The interval between administration of vecuronium and spontaneous recovery of TOF ratio to $>0.7$ was similar when monitored by AMG or EMG, at $49.1 \pm$ 10.5 and $50.0 \pm 9.0 \mathrm{~min}$, respectively (Figure 5). The bias between the sensors was one minute (AMG reaching TOF $>0.7$ earlier than EMG) with limits of agreement from -10 to $9 \mathrm{~min}$ (Figure 6) and $95 \% \mathrm{CI}$ for the 


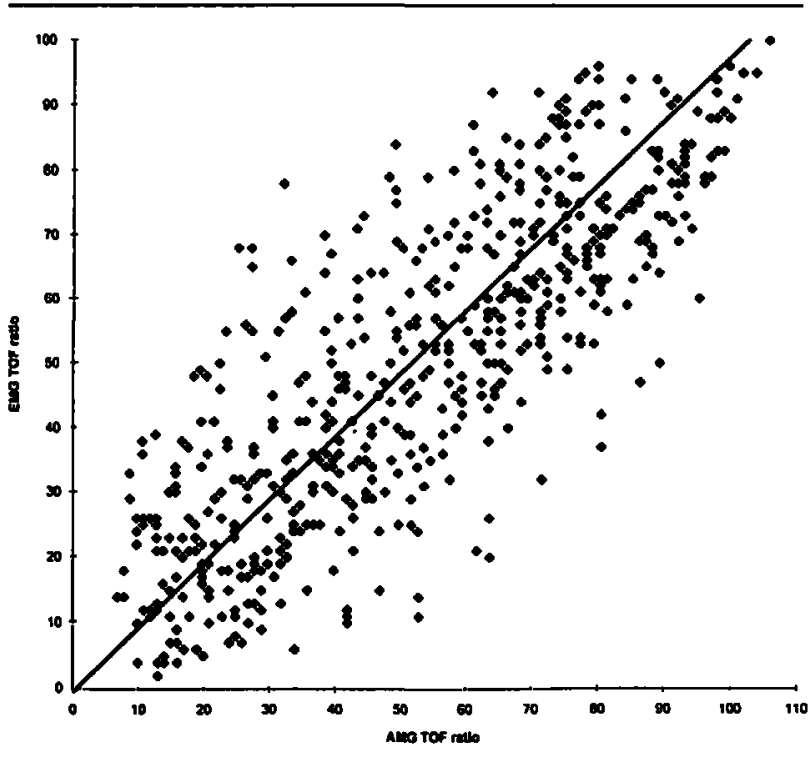

FIGURE 3 Comparison of TOF ratios monitored simultancously by EMG and AMG at all measurement points and line of identity.

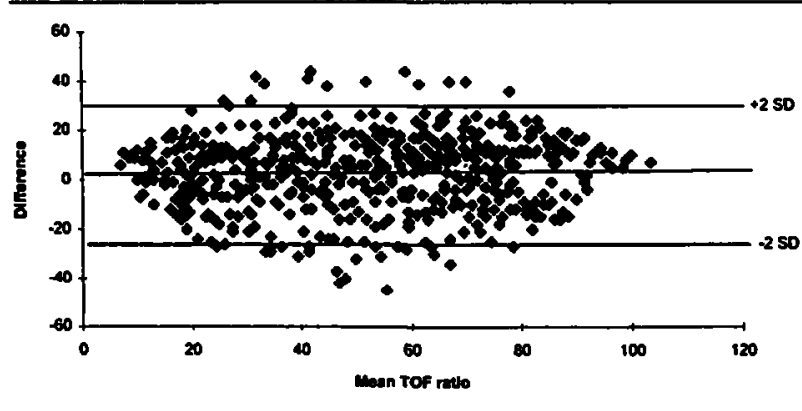

FIGURE 4 Difference between TOF ratios measured by AMG and EMG (as shown in Figure 3) plotted against their means, with limits of agreement indicated.

bias of $-1.0-3.0 \mathrm{~min}$. When the TOF ratio was $>0.7$ by EMG, the mean TOF ratio by AMG was similar at 0.72 \pm 0.14 (range: $0.39-0.93$ ).

\section{Discussion}

This study confirmed that fade in response to TOF stimulation was no longer visible $10 \mathrm{~min}$ before the TOF ratio was restored to the "gold standard" of 0.7 when monitored by AMG or EMG. Futhermore, the TOF ratio is 0.4 , whether monitored by AMG or EMG, despite apparent return to full recovery by clinical evaluation. These results suggest that there is a period of vulnerability during which a patient may be assumed to have recovered, but residual neuromuscular blockade is present to an extent which can compromise respiratory efforts. It is now recognised that return to a TOF ratio of

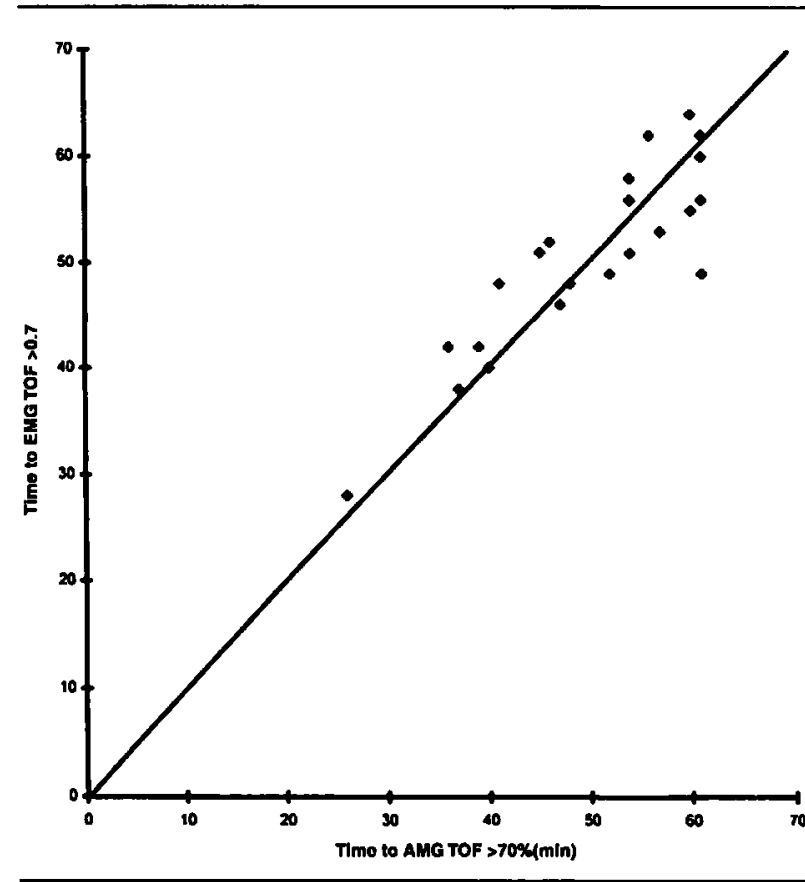

FIGURE 5 Times from injection of vecuronium $0.1 \mathrm{mg} \cdot \mathrm{kg}^{-1}$ iv to recover to TOF ratios $>0.7$ as assessed by AMG and EMG with line of identity shown.

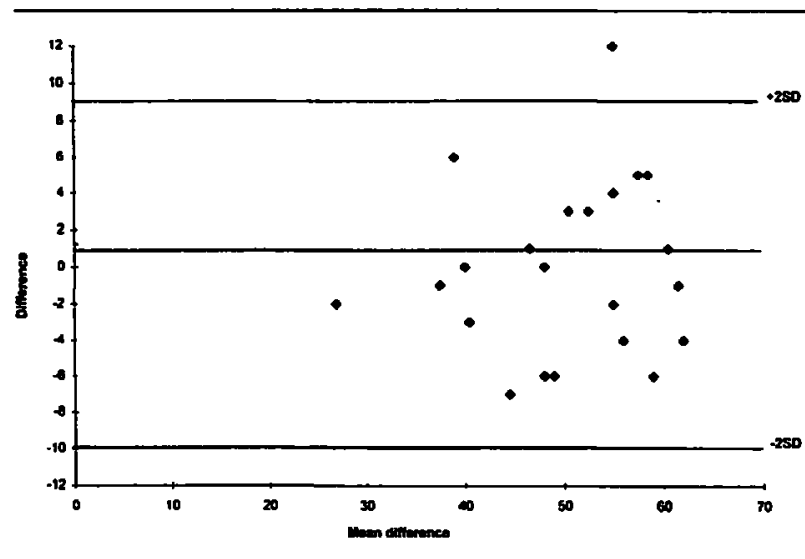

FIGURE 6 Difference between time $(\mathrm{min})$ to reach TOF ratio $>0.7$ measured by AMG and EMG plotted against the mean of the differences with limits of agreement shown.

0.7 may be a conservative estimate of the degree of recovery which is desirable at the end of surgery. ${ }^{5,13}$ Ventilatory depression may be seen until nearly complete recovery of TOF ratio to $\geq 0.9$ so that this period of vulnerability may be longer than ten minutes, even for a neuromuscular relaxant of intermediate duration, such as vecuronium.

Care was taken to minimize differences between the output of the two monitors due to study conditions. 
Electrode positioning was constant ${ }^{14}$ and movement of the arm from blood pressure measurement or tactile evaluation was avoided. A continuous infusion was not given, to minimize temperature changes. Repeated visual assessment of TOF response by the same observer may have introduced bias, but the observer was blinded to the AMG or EMG recordings. Tactile assessment was not made, but gives similar results to visual assessment. ${ }^{3-5}$ Variations in responses from different arms were avoided by randomization of the monitors to right or left arm. The characteristics of the monitors meant that AMG stimulation was applied every $15 \mathrm{sec}$ while that of the EMG was at $20 \mathrm{sec}$ intervals. The faster rate may intensify a measured block, but is unlikely to have influenced the detection of TOF fade appreciably. ${ }^{15}$

The finding in the present study that fade of TOF ratio $<0.4$ was not detected by visual observation agrees with previous studies, which have consistently shown that the ability to detect small degrees of fade clinically is unreliable and not improved by experience. ${ }^{3}$ The ability to detect residual neuromuscular blockade by tactile assessment of fade with double burst stimulation offers only modest improvement. ${ }^{4-7}$ Two previous studies compared the AMG with the mechanomyograph (MMG) ${ }^{16.17}$ or EMG. ${ }^{18}$ Comparisons were made using regression analysis or correlation coefficients and it was concluded that the two monitoring methods gave disparate results. In the present study comparisons were made by using the approach of Bland and Altman. ${ }^{11.12}$ The limits of agreement of the TOF ratio of 0.4 to 0.9 were found to be similar to those in the earlier studies, ${ }^{18}$ but the interpretation differs. In contrast to previous views, we consider that these limits of agreement between EMG and AMG are very acceptable when compared with their wide discrepancy with clinical assessment.

Limits of agreement in terms of time are, perhaps, more clinically relevant than is the TOF ratio. For example, with continuous monitoring following the administration of vecuronium, when the TOF ratio was $>0.7$ by AMG, the TOF ratio would exceed 0.7 by EMG in more than $95 \%$ of children after a further ten minutes. The major advantage of the AMG over the MMG and EMG is that it is as easy to use as a standard peripheral nerve stimulator. In all patients, the AMG was calibrated at the first attempt and readjustment was not required, while three patients were withdrawn from the study due to difficulties in obtaining an adequate EMG calibration, and readjustment was required in several others. The findings of this study only apply directly to children following the use of vecuronium and may not be reproduced in different age groups and with other muscle relaxants. However, it is likely that differences will result in longer or shorter "periods of vulnerability" resulting from the variable rates of recovery of different neuromuscular blocking agents or rates at different ages.

The EMG is impractical as an alternative to visual or tactile assessment of recovery from neuromuscular blockade in the operating room. Even if the TOF ratio were monitored by EMG, the degree of recovery which is adequate is controversial, ${ }^{19-21}$ and the use of a TOF ratio $>0.7$ to indicate adequate clinical recovery and $<0.5$ as an indicator of important residual neuromuscular blockade, may be conservative. Although monitoring by either the AMG or the EMG resulted in improved detection of residual neuromuscular blockade in the children studied, the AMG had the advantage of ease of use and was more dependable in its monitoring performance. Experience in adults is limited, but the use of AMG monitoring reduced the incidence of residual neuromuscular blockade after pancuronium administration. $^{10}$ It is concluded that the AMG is superior to clinical assessment in the detection of residual neuromuscular block in children. It is easy to use and provides an assessment of TOF ratio which is as useful as EMG monitoring.

\section{References}

1 Ali HH, Wilson RS, Savarese JJ, Kitz RJ. The effect of tubocurarine on indirectly elicited train-of-four muscle response and respiratory measurements in humans. $\mathrm{Br} \mathbf{J}$ Anaesth 1975; 47: 570-4.

2 EL Mikatii N, Wilson A, Pollard BJ, Healey TEJ. Pulmonary function and head lift during spontaneous recovery from pipecuronium neuromuscular block. $\mathrm{Br} \mathrm{J}$ Anaesth 1995; 74: 16-9.

3 Viby-Mogensen J, Jensen NH, Engbark J, Ørding $H$, Skovgaard LT, Chrammer-Jørgensen B. Tactile and visual evaluation of the response to train-of four nerve stimulation. Anesthesiology 1985; 63: 440-3.

4 Brull SJ, Silverman DG. Visual and tactile assessment of neuromuscular fade. Anesth Analg 1993; 77: 352-5.

5 Brull SJ. An update on monitoring of neuromuscualar function. Current Opinion in Anaesthesiology 1992; 5: 577-83.

6 Drenck NE, Ueda N, Olsen NV, et al. Manual evaluation of residual curarization using double burst stimulation: a comparison with train-of four. Anesthesiology 1989; 70: 578-81.

7 Saddler JM, Bevan JC, Donati F, Bevan DR, Pinto SR. Comparison of double-burst and train-of four stimulation to assess neuromuscular blockade in children. Anesthesiology 1990; 73: 401-3.

8 Viby-Mogensen J, Jensen E, Werner M, Kirkegaard Nielsen $\boldsymbol{H}$. Measurement of acceleration: a new method of 
monitoring ncuromuscular function. Acta Anaesthesiol

Scand 1988; 32: 45-8.

9 Engbaek J. Monitoring neuromuscular function. Current Opinion in Anaesthesiology 1989; 2: 479-83.

10 Mortensen CR, Berg H, El-Mahdy A, Viby-Mogensen J. Perioperative monitoring of neuromuscular transmission using acceleromyography prevents residual ncuromuscular block following pancuronium. Acta Anaesthesiol Scand 1995; 39: 797-801.

11 Bland JM, Altman DG. Statistical methods for assessing agreement between two methods of clinical measurcment. Lancet 1986; 1: 307-10.

12 Altman DG, Bland JM. Measurement in medicine: the analysis of method comparison studies. The Statistician 1983; 32: 307-17.

13 Eriksson LI, Sato M. Severinghaus JW. Effect of a vecuronium-induced partial neuromuscular block on hypoxic ventilatory response. Anesthesiology 1993; 78: 693-9.

14 Brull SJ, Silverman DG. Pulse width, stimulus intensity, electrode placement, and polarity during asssessment of neuromuscular block. Anesthesiology 1995; 83: 702-9.

15 Meretoja OA, Taivainen T, Brandom BW, Wirlavuori $K$. Frequency of train-of-four stimulation influences neuromuscular response. Br J Anaesth 1994; 72: 686-7.

16 Werner MU, Kirkegaard Nielsen H, May O, Djernes $M$. Assessment of ncuromuscular transmission by the evoked acceleration response. An evaluation of the accuracy of the acceleration transducer in comparison with a force displacement transducer. Acta Anaesthesiol Scand 1988; 32: 395-400.

17 Harper HJN, Martlew R, Strang T, Wallace M. Monitoring neuromuscular block by acceleromyography: comparison of the Mini-Accelograph with the Myograph $2000 . \mathrm{Br}$ J Anaesth 1994; 72: 411-4.

18 Meretoja OA, Werner MU, Wirtavuori K, Luosto T. Comparison of thumb acceleration and thenar EMG in a pharmacodynamic study of alcuronium. Acta Anaesthesiol Scand 1989; 33: 545-8.

19 Ali HH, Utting JE, Gray TC. Quantitative assessment of residual antidepolarizing block (Part ll). $\mathrm{Br} \mathrm{J}$ Anaesth 1971; 43: 478-85.

20 Kopman AF. The relationship of evoked electromyographic and mechanical responses following atracurium in humans. Anesthesiology 1985; 63: 208-11.

21 Dupuis JY, Martin R, Tétrault JP. Clinical, electrical and mechanical corrclations during recovery from neuromuscular blockade with vecuronium. Can J Anaesth 1990; 37: $192-6$. 